\title{
Sustainability priorities across the strategic and operational level in packaging development
}

\section{Bjorn de Koeijer (D) I Carsten Gelhard I Roland ten Klooster}

Department of Design, Production and Management, Faculty of Engineering Technology, University of Twente, Drienerlolaan 5, 7522NB, Enschede, the Netherlands

\section{Correspondence}

Bjorn de Koeijer, Department of Design, Production and Management, Faculty of Engineering Technology, University of Twente, Drienerlolaan 5, 7522 NB Enschede, the Netherlands.

Email: b.l.a.dekoeijer@utwente.nl
Sustainability is well-established in many companies' strategic postures. However, executing sustainability-related goals often lags at the operational level. This study analyses how decision-making processes in packaging development at different hierarchical levels are characterized in achieving a sustainability consensus.

This research focuses on the alignment of the strategic and operational levels of packaging development in relation to the integration of sustainability considerations. This materializes in a stakeholder perspective on packaging development and an analysis of targets aiming for the integration of sustainability considerations in such development processes. The involvement and decision making by internal stakeholders, the involvement of external stakeholders and sustainability target setting are considered as conditions causing the outcome of interest: levels of sustainability implementation on both the strategic and the operational levels of packaging development.

By using a set-theoretic method, we address that different compositions of stakeholder involvement and target setting might cause the same level of sustainability priority at the strategic and operational levels. For data analysis, we use a fuzzy-set qualitative comparative analysis ( $\mathrm{fQ} \mathrm{QCA}$ ) with empirical data derived from survey responses by packaging experts. This approach is motivated by its ability to address the complexity of the interplay of case characteristics within development processes. The research findings provide several indications of a limited alignment of a company's strategic sustainability ambition with the operational activities of multidisciplinary packaging development teams. The insights on the sustainability-related configurations of stakeholders and target setting provide guidance for managing projects across the strategic and operational levels in improving sustainable packaging development.

\section{KEYWORDS}

packaging development, strategic management, operations management, sustainability, fsQCA

This is an open access article under the terms of the Creative Commons Attribution License, which permits use, distribution and reproduction in any medium, provided the original work is properly cited.

(c) 2019 The Authors. Packaging Technology and Science published by John Wiley \& Sons Ltd 


\section{1 | INTRODUCTION}

Concerns about the negative environmental impact of human activity have fuelled corporate and governmental aims towards sustainable development. High-impact publications such as The Limits to Growth ${ }^{1}$ and Our Common Future ${ }^{2}$ showed the urgency of sustainability as a driver for development. In recent decades, the focus of sustainable product development has shifted from eco-efficient strategies to paradigms aiming for closed material cycles - such as Cradle to Cradle ${ }^{3,4}$ and Circular Economy. ${ }^{5}$ Currently, sustainability and circularity are increasingly considered as a source of competitive advantage for companies $^{6-8}$ and a key issue for company survivability. ${ }^{9}$ As a result, strategic sustainability aims are well-established in many companies' postures. Currently available research shows the alignment of both the strategic and the operational levels as a prerequisite for a successful integration of sustainability considerations in companies' new product development activities ${ }^{10-12}$ - aligning with stakeholder responsibility. ${ }^{13}$ However, currently, the operationalization of sustainability aims in product development processes seems to lag. ${ }^{14,15}$

Within the fast-moving consumer goods (FMCG) sector, packaging is a high-profile topic when considering sustainable development. Many companies address the development of product-packaging combinations - and specifically packaging as an isolated entity - as a relevant issue in their corporate social responsibility (CSR) aims. ${ }^{16,17}$ Examples of company-wide CSR communications, which explicitly address packaging development, include Unilever's Sustainable Living Plan $^{18}$ and Coca-Cola's 'Sustainable Packaging' aims. ${ }^{19}$

This study contributes to the discussion on the alignment of the strategic and operational levels of packaging development by analysing how decision-making processes at different hierarchical levels are characterized in achieving a consensus on the integration of sustainability. The involvement and decision-making processes by various stakeholders - both internal and external - influence the priority setting for sustainability at both the strategic and the operational levels of development, as hinted to by previous research. ${ }^{10,20,21}$ Building on this, we posit that the relative importance of these stakeholders differs across the strategic and the operational levels for prioritizing sustainability in packaging development processes.

By using a set-theoretic method - focusing on combinations of case characteristics ('sets') instead of individual factors - we address that different compositions of stakeholder involvement at the strategic and the operational levels might cause the same level of sustainability priority. For data analysis, we use a fuzzy-set qualitative comparative analysis (fsQCA), ${ }^{22,23}$ with empirical data derived from 36 survey responses among Dutch packaging experts. By disclosing which combinations of internal and external stakeholder involvement and decision-making roles align with high levels of sustainability integration at the strategic level as well as the operational level, this study provides valuable guidance for managing projects across the strategic and operational levels in achieving a sustainability consensus in packaging development.

The following section outlines the theoretical background of this research. This covers an exploration of the strategic and operational levels of packaging development, the relevance of a stakeholder perspective on sustainable packaging development and this study's main propositions. Next, we describe our research approach and the main findings. The paper concludes with a discussion and conclusions of the findings and suggestions for further research on this topic.

\section{2 | THEORETICAL BACKGROUND}

\section{1 | Strategic and operational sustainability}

In contrast to the traditional perspective on sustainable development - in line with the triple bottom line: balancing economic, social and environmental factors ${ }^{24}$ - this research focuses on the strategic and operational levels of sustainability in development processes. Current literature identifies a misalignment of the strategic and operational levels of sustainable development [e.g. De Koeijer et al. (2017), ${ }^{25}$ Hallstedt et al. (2013) ${ }^{14}$ and Van Hemel and Cramer (2002) ${ }^{15}$ ]. This research focuses on this misalignment, in relation to stakeholder involvement and decision making, and target setting in packaging development processes.

The strategic level of sustainable development includes a company's mission and vision and its strategic direction towards sustainable development. This materializes in overall objectives for sustainable development, related to product ranges or product development strategies, ${ }^{12}$ and represents a company's desired inclusion of sustainability considerations in development processes. Typically, such strategies cover short and long-term goals and are communicated via internally or publicly available policy documents and commercial publications. In this research, we consider the strategic level of packaging development by means of stakeholders' interpretation of their company's mission, vision and sustainability strategy.

The activities of multidisciplinary development teams - characterized by functional decisions ${ }^{26}$ made by stakeholders from various disciplines - constitute the operational level of sustainable development. During development processes, the desired sustainability considerations are incorporated in concrete development activities. This results in an achieved level of sustainability incorporated in developed products, as part of the outcome of the operational level of development. The combination of the intended and realized strategy composes a company's competitive environmental strategy. ${ }^{27}$ In this research, the operational level of development is analysed by means of stakeholders' interpretation of the concrete development efforts and achievements of packaging development teams.

\section{2 | Stakeholder perspective on sustainability}

For the consideration of CSR - with sustainability in packaging development processes as a subdomain - stakeholder theory poses a relevant research perspective., ${ }^{7,28}$ This relates to those groups and individuals who can influence development activities ${ }^{13,29}$ and jointly create value. ${ }^{28}$ The appointment of multidisciplinary development teams is generally identified as a relevant factor for the successful 
integration of sustainability considerations in development processes [e.g. by De Medeiros et al. (2014), ${ }^{30}$ García-Arca et al. $(2017)^{31}$ and Rotmans $(2006)^{32}$ ]. On top of that, management commitment is essential for a successful integration of sustainability considerations. ${ }^{11,14,33}$ When considering a supply chain as a cross-functional network of stakeholders, a product-packaging combination can be identified as a main element. ${ }^{16,34,35}$

In this research, the stakeholder perspective is covered by internal stakeholders' involvement and decision making and involvement of external stakeholders in development processes. Although decision making by internal stakeholders measures which internal stakeholders are responsible for the process of selecting a suitable design direction from predefined options, involvement of internal and external stakeholders measures which stakeholders participate in the process of preparing and executing those design directions. For the stakeholder interrelations, we distinguish between exploratory stakeholders (aimed at identifying new opportunities; e.g. marketing, packaging development and product development) and exploitative stakeholders (aimed at exploiting existing expertise; e.g. management, packaging engineering and procurement) ${ }^{36-39}$ within packaging development processes. Even though we acknowledge that stakeholder groups can be covered by both categories, we define all analysed stakeholders as either exploratory or exploitative.

The relation between the stakeholder perspective on packaging sustainability and the alignment of the strategic and the operational levels shapes this research's first proposition:

Proposition 1. Configurations of internal and external packaging development stakeholders that cause high levels of sustainability differ between the strategic and the operational levels.

\section{3 | Packaging development target setting for sustainability}

Packaging development has a subordinate role within 'generic' product development ${ }^{40,41}$ - it can be regarded as a field with a limited maturity level. In this research, packaging development is regarded as a separate category within generic product development via two packaging-specific features:

- The primary functions of packaging: product protection, enabling distribution and use and communication about the contained products $^{42-44}$;

- The role of packaging as a facilitator within a product-packaging combination: it acts as a beneficial add-on to a product, the integrated entity fulfils functions during different steps of a supply chain. ${ }^{41,45,46}$

The facilitator role of packaging results in a twofold environmental impact. ${ }^{47,48}$ The direct environmental impacts relate to the features of packaging itself as an isolated entity: for instance, regarding packaging material quantities and recyclability. Secondary environmental impacts of packaging relate to the role as a facilitator within a productpackaging combination. The primary functions of packaging should result in avoided negative product-related environmental impacts such as product loss - as a result of proper product protection, storage and transport. Because of this commensalism, it is incorrect to consider packaging in isolation from the contained product: a productpackaging combination is the relevant entity when considering sustainability. Therefore, we distinguish between targets aiming for integrated product-packaging development (reducing product waste and low-impact product-packaging) and targets related to an isolated perspective on packaging development (ecologic materials, minimal packaging weight, separable packaging materials and minimal packaging material). The relation between this target-setting perspective on packaging sustainability and the alignment of the strategic and the operational levels leads to the second proposition:

Proposition 2. Configurations of integrated and isolated packaging development targets that cause high levels of sustainability differ between the strategic and the operational levels.

Figure 1 visualizes this research's theoretical framework: the alignment of the strategic and operational levels of sustainable packaging development by focusing on configurations of internal and external stakeholders (Proposition 1) and development targets (Proposition 2). The figure addresses this research's core perspective by visualizing the mirroring of measuring Propositions 1 and 2 as causing the outcomes of interest: strategic and operational sustainability.

\section{3 | METHODOLOGY}

This study relies on a configurational approach, which assumes that configurations of case characteristics, rather than individual factors, cause the outcome of interest. ${ }^{49-51}$ Contrasting to traditional regression analysis, it allows to analyse attribute configurations for a more detailed description of causality patterns. ${ }^{51}$ Instead of considering the isolated net influence of each variable on the outcome, fsQCA the approach applied in this research - examines how variables combine to configurations to explain the outcome of interest [e.g. Ragin $(2008)^{22}$ and Woodside $(2013)^{23}$ ]. In this study, this relates to configurations that lead to high levels of sustainability integration with respect to the strategic and the operational levels. The use of fsQCA in the study at hand is motivated by its consideration of conjunction (i.e. the interplay of different attributes leads to the outcome) and equifinality (i.e. alternative combinations of attributes can lead to the same outcome). ${ }^{51-54}$

QCA is particularly suited for medium- $\mathrm{N}$ data sets (around 10 to 50 cases). ${ }^{49,55,56}$ The application of fsQCA for this study is eventually motivated by this combination of the suitability for medium- $\mathrm{N}$ data sets and the complexity of the interplay of case characteristics in sustainable packaging development from the perspective of stakeholder involvement and target setting. 
FIGURE 1 Theoretical framework

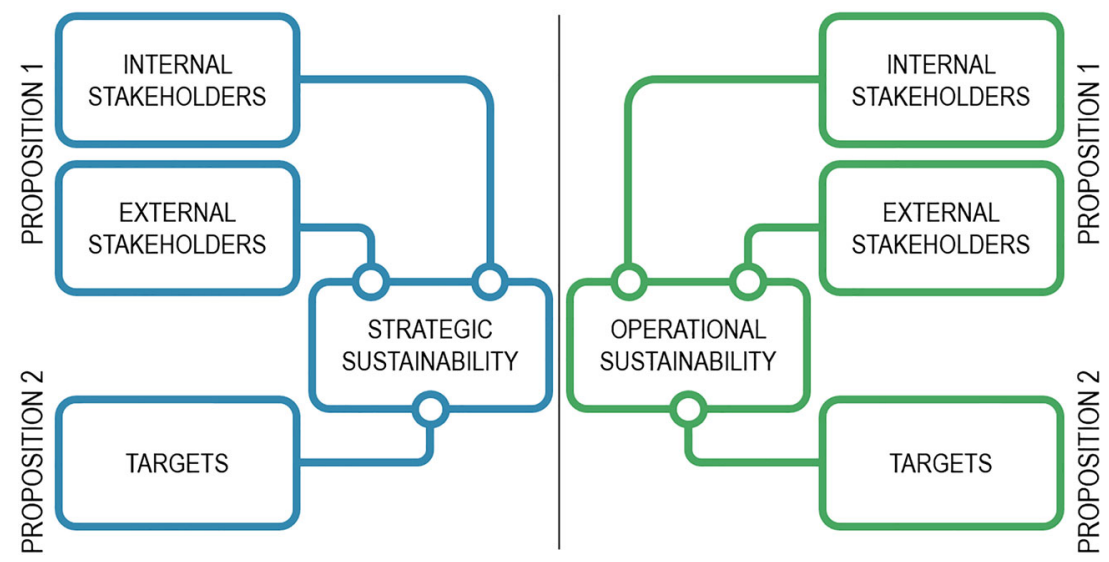

\section{1 | Data collection}

The empirical data of this study derives from 36 survey responses among Dutch packaging experts. The decision to focus on the Dutch packaging industry is based on the accessibility of this industry and the authors' familiarity with it. In the surveys, a selection of questions focused on the application of design briefs in sustainable packaging development processes, as described by Ten Klooster and De Koeijer (2016). ${ }^{57}$ For the current study, the survey sections on strategic and operational sustainability, internal and external stakeholder involvement and target setting for sustainable packaging development were selected.

In the survey, a combination of single- and multiple-choice questions (e.g. regarding the involvement of stakeholders), Likert scale questions (e.g. regarding the levels of sustainability) and open questions are presented to the respondents. Each multiple-choice question provided 5 to 12 predefined options, plus the option to select 'none', or to define a unique option. We do not limit the number of selected options per question. Open questions are applied as a basis for interpretation of the quantitative data in the data analysis process. Therefore, the respondents are not obligated to fill in answers to open questions. The relevant survey questions are listed in the Appendix.

The surveys were distributed online, via the Dutch Association of Packaging Professionals (Vereniging Nederlandse Verpakkingskundigen VNV) and the network of packaging design graduates from the University of Twente currently active in the packaging industry. The respondents to the survey are packaging development stakeholders from various disciplines (or a combination of disciplines), mainly packaging design (58\% of the respondents), packaging technology (42\%), product development (14\%), marketing (11\%) and management (8\%). They are primarily active in packaging development for food or non-food products, business-to-business packaging development, retail or at packerfillers (A-brand owners or private label companies). The data collection was not concentrated on a specific set of packaging types in order to derive comprehensive findings, which represent a broad scope within the product-packaging development sector. All surveys were distributed and returned in February and March 2016, with a response rate of $14 \%$. The respondents were presented with the option to remain anonymous to the researchers, unless they actively shared their contact information.

\section{2 | Measures}

As outcome variables, we measure the levels of sustainability implementation on the strategic company level (characterized by corporate responsibility efforts) and the operational level of packaging development (characterized by concrete sustainability implementations) following from the research's main propositions. The different conditions causing the outcomes of interest split up into

1a. Involvement of internal stakeholders (management, marketing, packaging development, packaging engineering, procurement and product development);

1b. Decision making by internal stakeholders (management, marketing, packaging development, packaging engineering, procurement and quality assurance);

2. Involvement of external stakeholders (design agencies, competition, packaging material supply, retail, consumers and packaging machine production); and

3. Packaging development target setting for sustainability (reducing product waste, low-impact product-packaging, ecologic materials, minimal packaging weight, separable packaging materials and minimal packaging material).

For every category of conditions, we selected these six most mentioned options from the survey responses for further analysis.

\section{3 | Data processing}

Data was analysed using the software package fs/QCA 2.5, following the standard procedure of an fsQCA. ${ }^{22,51}$ The first step of the analysis within fs/QCA 2.5 covers the calibration of the measured outcome variables into fuzzy sets. Based upon both empirical and theoretical knowledge, the cases' degree of membership (i.e. the answers of each individual respondent) in the sets of causal conditions and outcomes are determined. These cases' degrees range from 0 (full 
TABLE 1 Legend for Tables 2-5

\begin{tabular}{|ll|}
\hline Symbol & Condition \\
\hline$\otimes$ & Core condition present \\
\hline$\otimes$ & Peripheral condition present \\
\hline & Core condition absent \\
\hline & Peripheral condition absent \\
\hline
\end{tabular}

non-membership) to 1 (full membership) with a cross-over point of 0.50 (maximal ambiguity). ${ }^{22,51}$ These membership scores indicate to which level configurations are 'in' or 'out' the outcome solution (in this study, a high level of strategic or operational sustainability). For the (seven-point) Likert scale questions, we applied the following thresholds: 5 for full membership, 2 for full non-membership and 4 as the cross-over point. These thresholds are in accordance with a division of $70 \%, 50 \%$ and $30 \%$ of the maximum value.

Following this calibration, we constructed, redefined and analysed the 'truth table'. This table lists all different configurations relevant for causing the outcomes of interest ${ }^{22,58}$ and shows the nature of these configurations (core or peripheral). In line with prior research [see e.g. Fiss $(2011)^{51}$ ], we referred to parsimonious and intermediate solutions to distinguish between core and peripheral conditions. Core configurations indicate a strong relationship between the conditions and the outcome of interest, whereas peripheral configurations are of a more complementary nature, reinforcing the core conditions. ${ }^{22,51,52}$ In order to reduce the truth table to only meaningful configurations, we defined thresholds for both the frequency and consistency levels. The frequency level refers to the minimum number of cases that is required to consider a solution as causing the outcome. Because the present study comprises a relatively small sample size, one observation was set as threshold for the frequency level. In this study, the consistency levels range from 0.79 to 1.00 and are thus close to the generally recommended thresholds of 0.80 up to $0.95 .^{22,52}$ Solutions above this consistency level are considered as being sufficient for causing the outcome of interest, whereas solutions below this consistency level are considered as not sufficient. ${ }^{59}$

\section{4 | FINDINGS}

The findings derived from the processed survey response data are presented in the following sections. In each section, we address the findings that are relevant to (part of) the propositions, partly by means of the appropriate sections of the truth table (Tables 2-5). Each relevant configuration is listed in a column according to the relation with strategic sustainability (S1, S2, etc.) or operational sustainability (O1, $\mathrm{O} 2$, etc.) - each column represents one configuration, which consists of the presence or absence of core and peripheral conditions. For results presented in Tables $2-5$, we used Ragin and Fiss's (2008) ${ }^{60}$ notation (see Table 1), which derives from the interpretation of both the intermediate and parsimonious solution of Ragin's $(2008)^{22}$ truth table analysis.

In addition, the tables address the various configurations' parameters of fit $^{56,58,61}$ :

- Raw coverage: the degree to which a configuration explains the outcome;

- Unique coverage: the proportion of cases that can be explained exclusively by that configuration;

- Consistency: the degree to which a configuration is a subset of the outcome;

- Solution coverage: the proportion of the outcome explained by the complete set of configurations; and

- Solution consistency: the degree to which membership in the complete set of configurations is a subset of membership in the outcome.

\section{1 | Internal stakeholder involvement}

For the involvement of internal packaging development stakeholders, the configurations leading to high levels of either strategic or operational sustainability are different but share various similarities (Table 2). In all configurations, the involvement of marketing shows

TABLE 2 Internal stakeholder involvement as causal condition

\begin{tabular}{|c|c|c|c|c|c|c|c|}
\hline \multirow[b]{2}{*}{ Stakeholder type } & \multirow{2}{*}{$\begin{array}{l}\text { Stakeholder / } \\
\text { Parameter of fit }\end{array}$} & \multicolumn{3}{|c|}{ Strategic sustainability } & \multicolumn{3}{|c|}{ Operational sustainability } \\
\hline & & S1 & S2 & S3 & O1 & $\mathrm{O} 2$ & O3 \\
\hline \multirow[t]{3}{*}{ Exploratory stakeholders } & Marketing & $\bullet$ & & & & & \\
\hline & Packaging development & 0 & & & & $\otimes$ & $\bullet$ \\
\hline & Product development & $\bullet$ & $\bullet$ & $\otimes$ & $\bullet$ & $\bullet$ & $\otimes$ \\
\hline \multirow[t]{8}{*}{ Exploitative stakeholders } & Management & & 0 & - & & & $\bullet$ \\
\hline & Procurement & & $\bullet$ & $\otimes$ & $\otimes$ & $\bullet$ & $Q$ \\
\hline & Packaging engineering & & O & $\otimes$ & $\bullet$ & $\bullet$ & $\otimes$ \\
\hline & Raw coverage & .385 & .257 & .065 & .143 & .143 & .074 \\
\hline & Unique coverage & .191 & .063 & .065 & .143 & .143 & .074 \\
\hline & Consistency & .992 & .994 & 1.00 & .963 & .963 & 1.00 \\
\hline & Solution coverage & .512 & & & .361 & & \\
\hline & Solution consistency & .991 & & & .970 & & \\
\hline
\end{tabular}


TABLE 3 Internal stakeholder decision making as causal condition

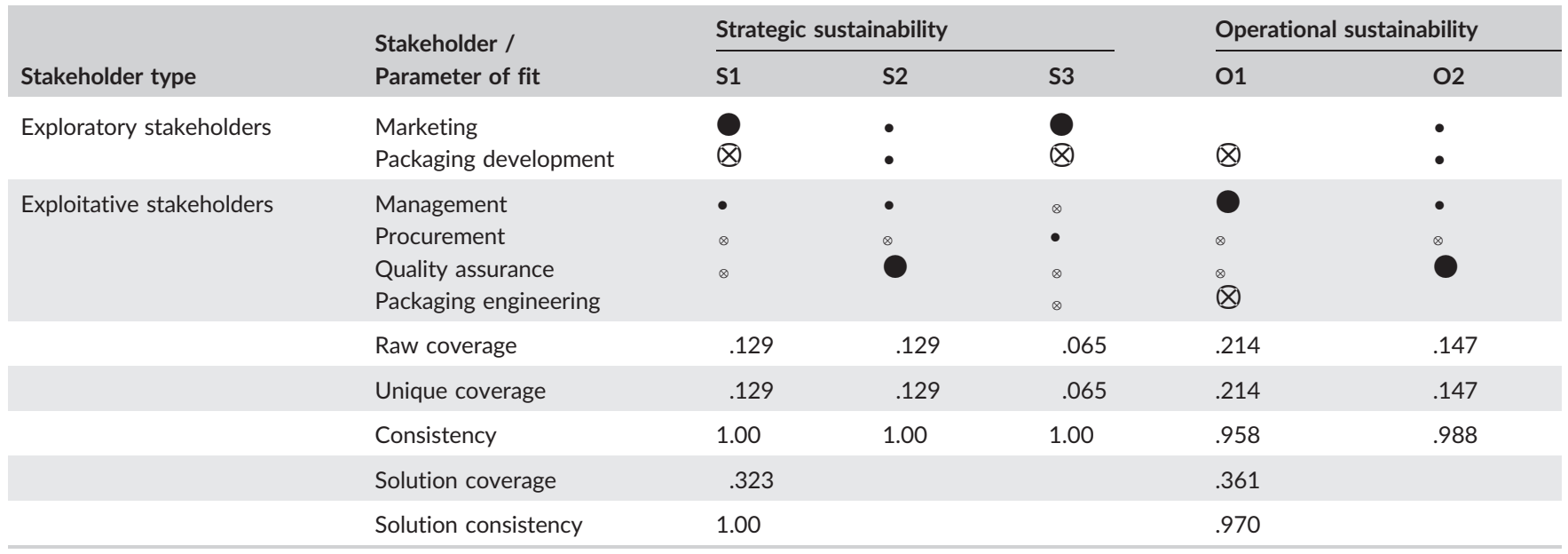

TABLE 4 External stakeholder involvement as causal condition

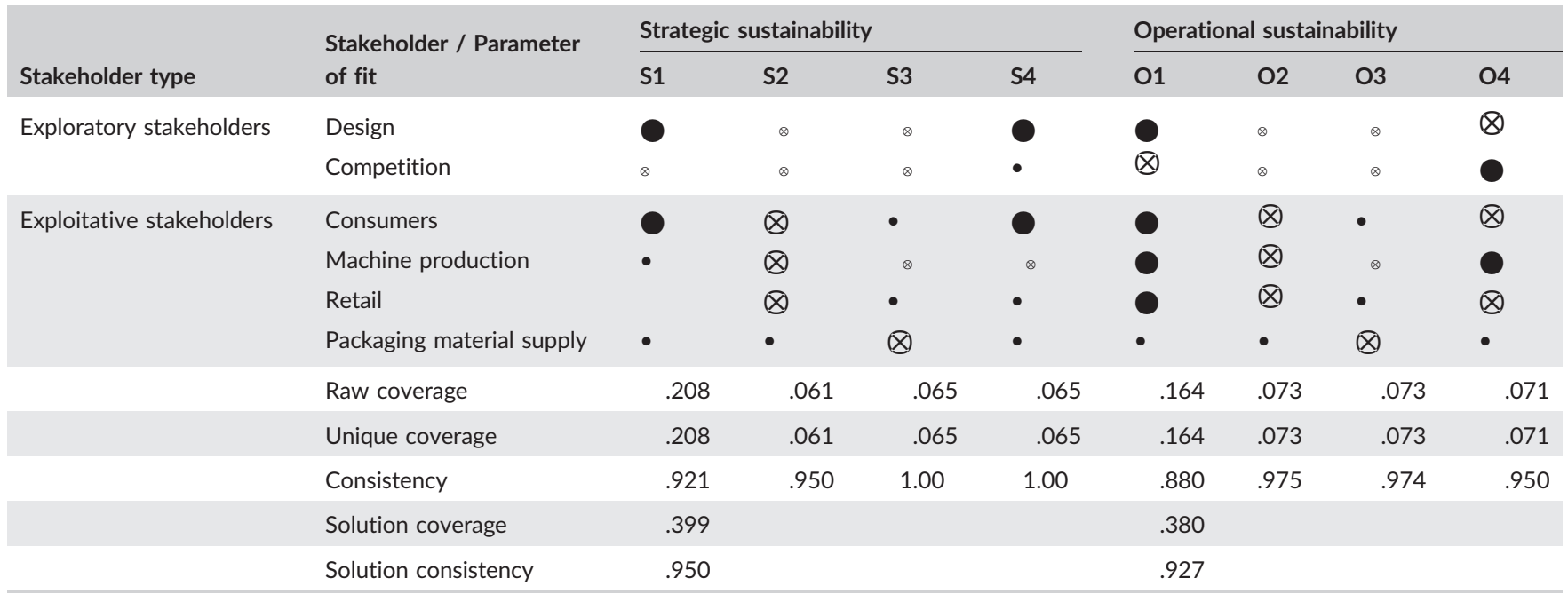

TABLE 5 Sustainability targets as causal conditions

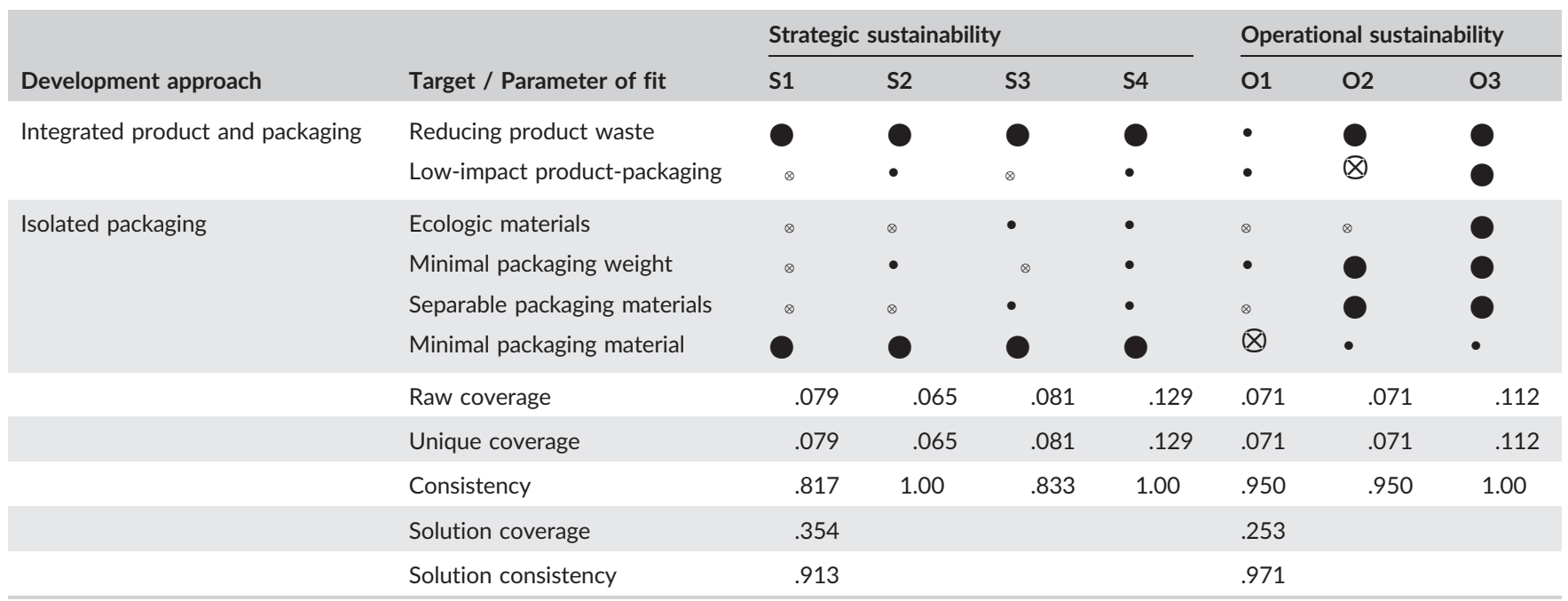

to be a critical condition. If the exploratory stakeholders are involved, packaging engineering is suggested as a relevant additional stakeholder for both levels of sustainability. For operational sustainability, this is complemented with an exclusion of procurement stakeholders. Configuration S2 suggests high strategic sustainability resulting from the involvement of all stakeholders, with a non-defined involvement 
or exclusion of packaging development stakeholders. The involvement of marketing, packaging development and management, plus the exclusion of product development, procurement and packaging engineering, is suggested as a relevant configuration for both high strategic sustainability and high operational sustainability. In general, for high operational sustainability, the configurations suggest a mutual exclusiveness between procurement and packaging development stakeholders.

\subsection{Internal stakeholder decision making}

When we further consider internal stakeholders, the configurations in Table 3 suggest decision making (or decisional participation ${ }^{8}$ ) by the exploratory stakeholders, management and quality assurance and the exclusion of procurement stakeholders as a relevant combination. The role of management is suggested as one of the main drivers of high operational sustainability. For configuration O1, management stakeholders are suggested as key decision makers, with an optional inclusion of marketing stakeholders. Decision making by marketing stakeholders is suggested as a leading condition for high strategic sustainability. Exclusive decision making by management and marketing stakeholders - combined with a possible inclusion of packaging engineering stakeholders - is suggested to result in high strategic sustainability (configuration S1) as is exclusive decision making by marketing and procurement stakeholders (configuration S3).

\section{3 | External stakeholder involvement}

Table 4 shows the configurations for both high strategic and operational sustainability in relation to the involvement of external stakeholders. For strategic sustainability, external designers are suggested as the most prevailing exploratory stakeholder to be involved. With regard to exploitative stakeholders, this holds for consumers and packaging materials suppliers. Exclusive involvement of packaging material suppliers (configurations S2 and O2) or the combined involvement of consumers and retailers (configurations S3 and $\mathrm{O} 3$ ) show to be relevant conditions for both high strategic sustainability and high operational sustainability. For high operational sustainability, the exclusion of competitors in combination with the involvement of the remaining analysed stakeholders is suggested as a relevant combination.

\section{4 | Target setting}

In addition to the involvement of stakeholders, companies' targetsetting regarding sustainable packaging is a relevant factor in analysing sustainability priorities. Table 5 shows the configurations for targets aiming for integrated product-packaging development and targets related to an isolated perspective on packaging development. The configurations regarding strategic packaging development targets suggest two leading targets: a reduction of product waste (an integrative target) and minimalizing packaging material amounts (an isolative target). The configurations show that the remaining four targets are mutually exclusive for strategic sustainability. The high relevance of a reduction of product waste as a relevant strategic target is mirrored by its relevance as an operational target. The configurations suggest that also a minimization of packaging weight is a highly relevant operational target. The combined consideration of all analysed packaging development targets is suggested as a relevant configuration for both high strategic and high operational sustainability (configurations S4 and $\mathrm{O} 3$ ).

\section{5 | DISCUSSION AND CONCLUSIONS}

In this study, the notion of complexity of the integration of sustainability in packaging development - on both the strategic and operational level - is leading. This complexity materializes in the involvement of various (multidisciplinary) stakeholders and different targets aimed at the integration of sustainability during packaging development processes. Motivated by this complexity in packaging development processes, data analysis by fsQCA is considered to be suited to derive relevant findings. The consideration of (multidisciplinary) stakeholders as a relevant influencer of packaging development processes adds to discussions on stakeholder theory in relation to sustainability in (more generic) development processes, such as Parmar (2010), ${ }^{28}$ Sharma and Henriques (2005) $)^{62}$ and Steurer et al. (2005). ${ }^{7}$

The four sets of conditions - internal stakeholder involvement and decision making, external stakeholder involvement and target setting suggest various relevant configurations for either high strategic or high operational sustainability in packaging development. The fsQCA discloses that many of the configurations that lead to high levels of sustainability integration differ between the strategic and the operational level, aligning with the research's propositions. This provides several indications of a limited alignment of a company's strategic sustainability ambition with the operational activities of multidisciplinary packaging development teams, aligning with other findings [e.g. Cassells and Lewis (2011), ${ }^{63}$ De Koeijer et al. (2017), ${ }^{25}$ Hallstedt et al. (2013) ${ }^{14}$ and Van Hemel and Cramer (2002) ${ }^{15}$ ].

Research indicates the appointment of multidisciplinary development teams as a success factor for sustainability-related consideration in development processes [e.g. De Medeiros (2014), ${ }^{30}$ García-Arca $(2017)^{31}$ and Johansson $(2002)^{11}$ ]. This research adds to this by acknowledging this factor and focusing on it in the data collection and analysis phases. The involvement of marketing stakeholders is suggested as a highly relevant condition for both high strategic and operational sustainability. On top of that, the involvement of packaging developers shows to be relevant as well. In isolated form, these findings are not remarkable; marketing and packaging development as lead stakeholders are recognized in currently available research, for example, by Petala et al. (2010), ${ }^{64}$ as is the relevance of a company's marketing-driven sustainability ambition [e.g. Kärnä et al. (2003), ${ }^{65}$ Storaker et al. (2013) ${ }^{66}$ and Van Hemel and Cramer(2002) $\left.{ }^{15}\right]$. When considering the strong suggestion of the exclusion of product development, procurement and packaging engineering - for both high strategic and high operational sustainability - the configurations 
display the significant relevance of the marketing-packaging development chain of involvement. Management's limited critical involvement in packaging sustainability can be interpreted as the manifestation of a role as motivator instead of executor. Such sustainability motivation or commitment role of management is recognized as a success factor for the integration of sustainability in development processes, for instance, by Boks (2006), ${ }^{10}$ Hallstedt et al. $(2013)^{14}$ and Johansson (2002). ${ }^{11}$

The configurations on decision making by internal stakeholders further suggest the relevance of marketing and management as lead stakeholders. However, we can identify two unexpected issues related to this process of decision making. First, decision making by marketers shows to be a critical condition for high strategic sustainability, and management decision making is a critical condition for operational sustainability. Second, for both high strategic and high operational sustainability, decision making by packaging development stakeholders shows to be limited. This contrasts our expectation of the critical decision-making roles of both marketing and packaging development stakeholders (the exploratory stakeholders) for high operational sustainability.

The involvement of external stakeholders suggests a limited influence of the exploratory stakeholders (designers and competitors) on either high strategic or high operational sustainability. The additional significant influence of packaging materials suppliers - an exploitative stakeholder - aligns with expectations: its established role as an essential link in packaging development processes. For operational sustainability, one configuration suggests the exclusion of competitors, in combination with the involvement of the remaining analysed stakeholders as a causal condition. For the packaging development sector, - of which a significant section represents FMCG producers and brand owners - this exclusion of competitors in relation to sustainable development is an interesting finding. Surprisingly, the configurations suggest that none of the external stakeholders act as a critical condition for either high strategic or high operational sustainability.

The configurations regarding strategic packaging development targets show a number of remarkable issues. The first being that a reduction of product waste (an integrative target) is the only critical condition identified in this analysis; the high relevance of a reduction of product waste as a relevant strategic target is mirrored by its relevance as an operational target. Minimalizing packaging material amounts (an isolative target) acts as the second leading target, mainly for high levels of strategic sustainability. Findings by De Koeijer et al. $(2017)^{25}$ indicate that the perceived operational considerations of integrated product-packaging development can be ambiguous in practice. This can be regarded as an indication of the misalignment between the strategic and operational levels of development, which is underlined by this research's findings in Table 5. In addition, the configurations show that the remaining four targets are mutually exclusive for strategic sustainability. The combined consideration of all analysed packaging development targets is suggested as a relevant configuration for both high strategic and high operational sustainability. Unexpectedly, the influence of the use of 'ecologic packaging materials' as an operational target is suggested to be limited.
The research findings lead to valuable insights into the alignment of the strategic and the operational levels of product-packaging development by focusing on decision-making processes in relation to the integration of sustainability-related considerations. Following the research propositions, we find that the involvement and decision making by internal and external stakeholders and target setting influence the resulting levels of strategic and operational sustainability. The research shows a number of critical findings, including the key role of marketing stakeholders, the limited decision-making power by packaging development stakeholders and the ambiguity of target setting for integrated product-packaging sustainability. This underlines the indicated misalignment of the strategic and operational levels of product-packaging development in relation to sustainability considerations, adding to previous research on this topic [e.g. Boks (2006), ${ }^{10}$ Prendergast and Pitt $(1996)^{20}$ and Wagner $(2015)^{21}$ ].

\section{I LIMITATIONS AND FUTURE RESEARCH}

A number of limitations can be identified in this research, related to the study design, the survey topics and the data analysis approach. One significant limitation is the background information distributed in conjunction with the surveys. The respondents were aware of the researchers' focus on packaging sustainability, which might lead to answers biased towards higher levels of strategic and operational sustainability. Second, in the data analysis process, only the six most mentioned answers per topic were selected. Other answers which may still provide relevant insights are not analysed.

Another relevant limitation relates to the subjectivity and interpretation requirements of the surveys. Because all respondents can be identified as internal stakeholders in packaging development processes, the outcome values of the strategic level and the influence of external stakeholders are merely measured via internal stakeholders' interpretations. The sources of the companies' sustainability strategies are not part of this study. From this viewpoint, this research's findings indicate relevant findings for industry. With the strategic consideration of product-packaging sustainability as a relevant topic for many companies, - as addressed in the introduction the further alignment with operational processes is key. The alignment of the strategic and operational levels must result in a more firmly established marketing proposition with regard to sustainabilityfocused packed products, ranging from the packaging's material contents to sustainability-related communication towards consumers. This research points towards the relevance of internal and external stakeholders' involvement and decision making and target setting, which may aid this alignment.

The research findings pose several promising directions for future research. This research may act as a basis for research into the more rigorous alignment of the strategic and operational levels of (sustainable) packaging development. This includes research into the background and development process of sustainability strategies including strategic target setting - and the level of knowledge on strategic sustainability targets within operational development teams. 
Second, the findings and conclusions as presented in this article may be valuable for other types of development, beyond packaging. The alignment of the strategic and operational levels of 'generic' product development and the integration of sustainability considerations in these processes can benefit from this research's focus on stakeholder theory and target setting and the added value of a configurational approach.

Finally, future research deriving from this study might focus on the practical interactions and interrelations within development teams. In addition to regarding a development team as a collection of disciplines, considering integrated development teams might show to be a relevant factor in aligning the strategic and operational levels of sustainable packaging development.

\section{ACKNOWLEDGEMENTS}

The authors wish to thank the Dutch Association of Packaging Professionals (Vereniging Nederlandse Verpakkingskundigen; VNV) for their assistance in distributing the surveys.

\section{ORCID}

Bjorn de Koeijer (D) https://orcid.org/0000-0002-7046-6290

\section{REFERENCES}

1. Meadows DH, Meadows DL, Randers J, Behrens WW III. The limits to growth. New York, United States: Universe Books; 1972.

2. World Commission on Environment and Development. Our common future. Oxford, United Kingdom: Oxford University Press; 1987.

3. McDonough W, Braungart M. Cradle to cradle: Remaking the way we make things. New York, United States: North Point Press; 2002.

4. McDonough W, Braungart M. The upcycle: Beyond sustainabilityDesigning for abundance. New York, United States: North Point Press; 2013.

5. Ellen MacArthur Foundation. Towards the circular economy Vol. 1. Cowes, United Kingdom: Ellen MacArthur Foundation Publishing; 2012.

6. Gelhard C, Von Delft S. The role of organizational capabilities in achieving superior sustainability performance. Journal of Business Research. 2016;69(10):4632-4642. https://doi.org/10.1016/j.jbusres.2016.03. 053

7. Steurer R, Langer ME, Konrad A, Martinuzzi A. Corporations, stakeholders and sustainable development I: A theoretical exploration of business-society relations. Journal of Business Ethics. 2005;61(3): 263-281. https://doi.org/10.1007/s10551-005-7054-0

8. Green AO, Hunton-Clarke L. A typology of stakeholder participation for company environmental decision-making. Business Strategy and the Environment. 2003;12(5):292-299. https://doi.org/10.1002/bse.371

9. Perez-Sanchez D, Barton JR, Bower D. Implementing environmental management in SMEs. Corporate Social Responsibility and Environmental Management. 2003;10(2):67-77. https://doi.org/10.1002/csr.37

10. Boks C. The soft side of ecodesign. Journal of Cleaner Production. 2006;14(15):1346-1356. https://doi.org/10.1016/j.jclepro.2005.11. 015

11. Johansson G. Success factors for integration of ecodesign in product development: A review of state of the art. Environmental Management and Health. 2002;13(1):98-107. https://doi.org/10.1108/0956616021 0417868
12. Simon M, Poole S, Sweatman A, Evans S, Bhamra T, Mcaloone T. Environmental priorities in strategic product development. Business Strategy and the Environment. 2000;9(6):367-377. https://doi.org/ 10.1002/1099-0836(200011/12)9:6<367::AID-BSE262>3.0.CO;2-D

13. Freeman RE, Harrison JS, Wicks AC, Parmar B, De Colle S. Stakeholder theory: The state of the art. New York, United States: Cambridge University Press; 2010.

14. Hallstedt SI, Thompson AW, Lindahl P. Key elements for implementing a strategic sustainability perspective in the product innovation process. Journal of Cleaner Production. 2013;51:277-288. https://doi.org/ 10.1016/j.jclepro.2013.01.043

15. Van Hemel C, Cramer J. Barriers and stimuli for ecodesign in SMEs. Journal of Cleaner Production. 2002;10(5):439-453. https://doi.org/ 10.1016/S0959-6526(02)00013-6

16. De Lange J, Oude Luttikhuis E, Ten Klooster R, Lutters E. Towards integrating sustainability in the development of product/packaging combinations. Bochum, Germany: 23rd CIRP Design Conference; 2013.

17. Nilsson F, Olsson A, Wikström F. Toward sustainable goods flows: A framework from a packaging perspective. Harstad, Norway: 23rd NOFOMA Conference; 2011.

18. Unilever NV. Waste \& packaging, 2017: https://www.unilever.com/ sustainable-living/the-sustainable-living-plan/reducing-environmentalimpact/waste-and-packaging/.

19. The Coca-Cola Company. Sustainable packaging, 2017: http://www. coca-colacompany.com/learn-more-about-sustainable-packaging/. Accessed on August 29, 2017.

20. Prendergast G, Pitt L. Packaging, marketing, logistics and the environment: Are there trade-offs? International Journal of Physical Distribution \& Logistics Management. 1996;26(6):60-72. https://doi. org/10.1108/09600039610125206

21. Wagner M. The link of environmental and economic performance: Drivers and limitations of sustainability integration. Journal of Business Research. 2015;68(6):1306-1317. https://doi.org/10.1016/j.jbusres. 2014.11.051

22. Ragin CC. Redesigning social inquiry: Fuzzy sets and beyond. Chicago United States: University of Chicago Press; 2008.

23. Woodside AG. Moving beyond multiple regression analysis to algorithms: Calling for adoption of a paradigm shift from symmetric to asymmetric thinking in data analysis and crafting theory. Journal of Business Research. 2013;66(4):463-472. https://doi.org/10.1016/j. jbusres.2012.12.021

24. Elkington J. Cannibals with forks: The triple bottom line of 21st century business. Oxford, United Kingdom: Capstone Publishing, Ltd.; 1997.

25. De Koeijer B, De Lange J, Wever R. Desired, perceived, and achieved sustainability: Trade-offs in strategic and operational packaging development. Sustainability. 2017;9(10):1923. https://doi.org/10.3390/ su9101923

26. Rivera-Camino J. Re-evaluating green marketing strategy: A stakeholder perspective. European Journal of Marketing. 2007;41(11/ 12):1328-1358. https://doi.org/10.1108/03090560710821206

27. Journeault M, De Rongé Y, Henri J-F. Levers of eco-control and competitive environmental strategy. The British Accounting Review. 2016;48(3):316-340. https://doi.org/10.1016/j.bar.2016.06.001

28. Parmar BL, Freeman RE, Harrison JS, Wicks AC, De Colle S, Purnell L. Stakeholder theory: The state of the art. Academy of Management Annals. 2010;4(1):403-445. https://doi.org/10.1080/19416520.2010. 495581

29. Freeman RE, Wicks AC, Parmar B. Stakeholder theory and "the corporate objective revisited". Organization Science. 2004;15(3):364-369. https://doi.org/10.1287/orsc.1040.0066 
30. De Medeiros JF, Ribeiro JLD, Cortimiglia MN. Success factors for environmentally sustainable product innovation: A systematic literature review. Journal of Cleaner Production. 2014;65:76-86. https://doi.org/ 10.1016/j.jclepro.2013.08.035

31. García-Arca J, Trinidad González-Portela Garrido A, Carlos PradoPrado J. "Sustainable packaging logistics". The link between sustainability and competitiveness in supply chains. Sustainability. 2017; 9 (7): 1098. DOI: 10.3390/su9071098.

32. Rotmans J. Tools for integrated sustainability assessment: A two-track approach. The Integrated Assessment Journal. 2006;6(4):35-57.

33. Jansson J, Nilsson J, Modig F, Hed VG. Commitment to sustainability in small and medium-sized enterprises: The influence of strategic orientations and management values. Business Strategy and the Environment. 2017;26(1):69-83. https://doi.org/10.1002/bse. 1901

34. Molina-Besch K, Pålsson H. Packaging for eco-efficient supply chains: Why logistics should get involved in the packaging development process. In: Macharis C, Melo S, Woxenius J, van Lier T, eds. Sustainable Logistics (Transport and Sustainability), Vol. 6: Emerald Group Publishing Ltd., 2014: 137-163.

35. Oude Luttikhuis EJ, De Lange J, Lutters E, Ten Klooster R. Using actor networks in decision making during content-packaging development. Procedia CIRP. 2014;15:419-424. https://doi.org/10.1016/j.procir. 2014.06.004

36. Hoang $\mathrm{H}$, Rothaermel FT. Leveraging internal and external experience: Exploration, exploitation, and R\&D project performance. Strategic Management Journal. 2010;31(7):734-758. https://doi.org/10.1002/ smj.834

37. Kyriakopoulos K, Moorman C. Tradeoffs in marketing exploitation and exploration strategies: The overlooked role of market orientation. International Journal of Research in Marketing. 2004;21(3):219-240. https://doi.org/10.1016/j.jiresmar.2004.01.001

38. Laureiro-Martínez D, Brusoni S, Zollo M. The neuroscientific foundations of the exploration-exploitation dilemma. Journal of Neuroscience, Psychology, and Economics. 2010;3(2):95-115. https://doi.org/10. 1037/a0018495

39. Sirmon DG, Hitt MA, Ireland RD. Managing firm resources in dynamic environments to create value: Looking inside the black box. Academy of Management Review. 2007;32(1):273-292. https://doi.org/10.5465/ AMR.2007.23466005

40. Azzi A, Battini D, Persona A, Sgarbossa F. Packaging design: General framework and research agenda. Packaging Technology and Science. 2012;25(8):435-456. https://doi.org/10.1002/pts.993

41. De Koeijer B, Wever R, Henseler J. Realizing product-packaging combinations in circular systems: Shaping the research agenda. Packaging Technology and Science. 2017;30(8):443-460. https://doi.org/10.1002/ pts.2219

42. Bramklev C. Towards integrated product and package development [Doctoral Thesis]. Lund, Sweden: Department of Design Sciences, Faculty of Engineering, Lund University; 2007.

43. Lutters D, Ten Klooster R. Functional requirement specification in the packaging development chain. CIRP Annals - Manufacturing Technology. 2008;57(1):145-148. https://doi.org/10.1016/j.cirp.2008.03. 052

44. Selke SEM. Green packaging. In: Boye JI, Arcand Y, eds. Green technologies in food production and processing. New York, United States: Springer Science+Business Media; 2012:443-468.

45. Bramklev C. On a proposal for a generic package development process. Packaging Technology and Science. 2009;22(3):171-186. https://doi. org/10.1002/pts.850
46. Grönman K, Soukka R, Järvi-Kääriäinen T, et al. Framework for sustainable food packaging design. Packaging Technology and Science. 2013;26(4):187-200. https://doi.org/10.1002/pts.1971

47. Wikström F, Williams $\mathrm{H}$, Venkatesh $\mathrm{G}$. The influence of packaging attributes on recycling and food waste behaviour-An environmental comparison of two packaging alternatives. Journal of Cleaner Production. 2016;137:895-902. https://doi.org/10.1016/j.jclepro.2016.07.097

48. Williams $H$, Wikström $F$, Löfgren $M$. A life cycle perspective on environmental effects of customer focused packaging development. Journal of Cleaner Production. 2008;16(7):853-859. https://doi.org/ 10.1016/j.jclepro.2007.05.006

49. Devers KJ, Cafarella Lallemand N, Burton RA, Kahwati L, McCall N, Zuckerman S. Using qualitative comparative analysis (QCA) to study patient-centered medical homes. Washington, United States: Urban Institute; 2013.

50. Fiss PC. A set-theoretic approach to organizational configurations. Academy of Management Review. 2007;32(4):1180-1198. https://doi. org/10.5465/AMR.2007.26586092

51. Fiss PC. Building better causal theories: A fuzzy set approach to typologies in organization research. Academy of Management Journal. 2011;54(2):393-420. https://doi.org/10.5465/AMJ.2011.60263120

52. Muñoz $P$, Dimov D. The call of the whole in understanding the development of sustainable ventures. Journal of Business Venturing. 2015;30(4):632-654. https://doi.org/10.1016/j.jbusvent.2014.07.012

53. Ragin CC. Fuzzy-set social science. Chicago, United States: University of Chicago Press; 2000.

54. Schneider CQ, Wagemann C. Standards of good practice in qualitative comparative analysis (QCA) and fuzzy-sets. Comparative Sociology. 2010;9(3):397-418. https://doi.org/10.1163/156913210X 12493538729793

55. Kane H, Lewis MA, Williams PA, Kahwati LC. Using qualitative comparative analysis to understand and quantify translation and implementation. Translational Behavioral Medicine. 2014;4(2):201-208. https://doi.org/10.1007/s13142-014-0251-6

56. Legewie N. An introduction to applied data analysis with qualitative comparative analysis (QCA). Forum Qualitative Sozialforschung/Forum: Qualitative Social Research. 2013; 14 (3). DOI: 10.17169/fqs-14.3.1961.

57. Ten Klooster R, De Koeijer B. Utilising the potential of design briefs in sustainable packaging development. 20th IAPRI World Conference on Packaging, 2016; Campinas, Brazil.

58. Cuadrado-Ballesteros B, Martínez-Ferrero J, García-Sánchez IM. Board structure to enhance social responsibility development: A qualitative comparative analysis of US companies. Corporate Social Responsibility and Environmental Management. 2017;24(6):524-542. https://doi.org/ 10.1002/csr.1425

59. Tóth Z, Thiesbrummel C, Henneberg SC, Naudé P. Understanding configurations of relational attractiveness of the customer firm using fuzzy set QCA. Journal of Business Research. 2015;68(3):723-734. https:// doi.org/10.1016/j.jbusres.2014.07.010

60. Ragin CC, Fiss PC. Net effects analysis versus configurational analysis: An empirical demonstration. In: Ragin CC, ed. Redesigning social inquiry: Fuzzy sets and beyond. Chicago, United States: University of Chicago Press; 2008:190-212.

61. Roig-Tierno N, Gonzalez-Cruz TF, Llopis-Martinez J. An overview of qualitative comparative analysis: A bibliometric analysis. Journal of Innovation \& Knowledge. 2017;2(1):15-23. https://doi.org/10.1016/j. jik.2016.12.002

62. Sharma S, Henriques I. Stakeholder influences on sustainability practices in the Canadian forest products industry. Strategic Management Journal. 2005;26(2):159-180. https://doi.org/10.1002/smj.439 
63. Cassells S, Lewis K. SMEs and environmental responsibility: Do actions reflect attitudes? Corporate Social Responsibility and Environmental Management. 2011;18(3):186-199. https://doi.org/10.1002/csr.269

64. Petala E, Wever R, Dutilh C, Brezet $\mathrm{H}$. The role of new product development briefs in implementing sustainability: A case study. Journal of Engineering and Technology Management. 2010;27(3):172-182. https://doi.org/10.1016/j.jengtecman.2010.06.004

65. Kärnä J, Hansen E, Juslin H. Social responsibility in environmental marketing planning. European Journal of Marketing. 2003;37(5/6):848-871. https://doi.org/10.1108/03090560310465170

66. Storaker A, Wever R, Dewulf K, Blankenburg D. Sustainability in frontend innovation at design agencies. Jeju Island, South Korea: 8th International Symposium on Environmentally Conscious Design and Inverse Manufacturing; 2013.

How to cite this article: de Koeijer B, Gelhard C, ten Klooster R. Sustainability priorities across the strategic and operational level in packaging development. Packag Technol Sci. 2019;32:618-629. https://doi.org/10.1002/pts.2480

\section{APPENDIX A.}

\section{SURVEY QUESTIONS}

The survey sections that are relevant for this research are presented in this appendix. The surveys were presented in Dutch; this appendix lists translated questions. Behind each question, the answering option is addressed. Every section in this appendix represents a separate page of the online surveys; this is helpful in limiting the risk of respondents being intimidated by the number of questions.

\section{A.1. | Introduction}

The first page of the survey introduces the topic (the implementation of sustainability considerations in packaging development processes) and the aim of the research (collecting insights in the current approach and status of this implementation). Besides that, it informs the respondent about the types of questions and provides an indication of the estimated time effort (15 to $20 \mathrm{~min}$ ). Finally, the introduction page addresses the process of handling the respondent's answers, emphasizing full anonymity.

\section{A.2. | Importance of sustainability}

1. What is the importance of packaging sustainability? (Seven-point Likert scale)

2. Could you clarify your answer? (Open question)

3. What is the importance of sustainability in your sector? (Sevenpoint Likert scale)

4. Could you clarify your answer? (Open question)

5. What is the importance of sustainability in your company's vision? (Seven-point Likert scale)

6. Can you clarify your answer? (Open question)

\section{A.3. | Target setting}

7. Strategic level: Which sustainability targets are important, related to packaging development? (Multiple-choice question: 12 predefined options, plus the option to select 'none' or define 'other')

8. Requirements: Which sustainability targets are important, related to packaging development? (Multiple-choice question: 12 predefined options, plus the option to select 'none' or define 'other')

9. Packaging development (realization): Which sustainability targets are important? (Multiple-choice question: 12 predefined options, plus the option to select 'none' or define 'other')

10. In relation to which targets does your company aim for an innovative role, by means of packaging development? (Multiple-choice question: 12 predefined options, plus the option to select 'none' or define 'other')

11. To what extent does your company succeed in realizing its strategic sustainability targets in specific packaging development projects? (Four-point Likert scale)

12. Can you clarify your answer? (Open question)

\section{A.4. | Stakeholders}

13. Which internal stakeholders are involved in packaging development (realization)? (Multiple-choice question: 8 predefined options, plus the option to select 'none' or define 'other')

14. What are their interests? (Open question)

15. Which internal stakeholders make decisions in packaging development (realization)? (Multiple-choice question: 8 predefined options, plus the option to select 'none' or define 'other')

16. What are their interests? (Open question)

17. Which external stakeholders are involved in packaging development? (Multiple-choice question: 10 predefined options, plus the option to select 'none' or define 'other')

18. What are their interests? (Open question)

\section{A.5. | Operational sustainability}

19. What is the importance of sustainability in packaging development (realization)? (Seven-point Likert scale)

20. Which aspects are more important than sustainability in packaging development (realization)? (Multiple-choice question: 5 predefined options, plus the option to select 'none' or define 'other')

21. Can you clarify your answers? (Open question)

22. Does your company address the extension of knowledge and experience on sustainability in packaging development, to align to the mission, vision, and sustainability targets? (Single-choice question: yes/no/unknown)

23. If yes: how? (Open question) 


\section{A.6. | Auxiliary questions}

24. In which discipline are you employed? (Multiple-choice question: 6 predefined options, plus option to define 'other')

25. How many years of experience do you have in this discipline? (Single-choice question: 5 predefined options)
26. What is your background (education/training)? (Multiple-choice question: 6 predefined options, plus option to define 'other')

In which sector are you employed? (Multiple-choice question: 6 predefined options, plus option to define 'other') 